\title{
The research of corrosion resistance of aluminum-bronze surfacing layer
}

\author{
SU Yun-hai, LIU Guang-chao, WU De-guang, LIU Zheng-jun
}

School of Material Science and Engineering, Shenyang University of Technology,

Shenyang, China, 110870.

Keywords:aluminum-bronze, plasma arc surfacing, corrosion resistance, microstructure

\begin{abstract}
Aluminum-bronze was surfacing on low carbon steel in different surfacing conditions by using reverse polarity weak plasma arc. The microstructure of surfacing layer has been studied by means of optical metallograghy and X-ray diffraction. The behavior of electrochemical corrosion in $\mathrm{PH}=8.0,3.5 \% \mathrm{NaCl}$ solution has been studied by using the Tafel polarization method. The results show that the corrosion of al-bronze surfacing layer performs best in $3.5 \% \mathrm{NaCl}$ solution; when surfacing current is $90 \mathrm{~A}$, the al-bronze surfacing layer obtains the best corrosion resistance. Then, with the increasing of surfacing current, the corrosion resistance of surfacing layer is getting worse. The microstructure is compose of $(\alpha+\gamma)$ phase and $\alpha$-phase. The $(\alpha+\gamma)$ phase suffers a
\end{abstract} dealminization preferentially, $\alpha$-phase has the best corrosion resistance.

\section{Introduction}

Copper-based alloys have good mechanical performance, formability and thermal conductivity, it also has good corrosion resistance in the marine environment. Among $\mathrm{Cu}$-based alloys, al-bronzes are used extensively because they possess superior properties such as high strength, oxidation and corrosion resistance, abrasion, wear, cavitation and erosion resistance, and impact resistance ${ }^{[1]}$. In order to offset the deficiency of the cast iron and steel, the copper alloy was surfacing on them, which can improve the mechanical performance, economic performance and application prospect. In recent years, a lot of researches have paid more attention to the microstructure and mechanical properties of Al-bronze alloys, corrosion behavior and the corrosion mechanism. But the corrosion behavior of al-bronze surfacing layer are very few. So, the corrosion resistance of Al-bronze surfacing layer which is made by welding al-bronze alloy powder on the steel of $20 \mathrm{~g}$ will been studied in this paper.

\section{Test materials and methods}

The al-bronze self-fluxing alloy powder was surfaced on $20 \mathrm{~g}$ steel plates by self-fluxing LU500-4 plasma arc welder. The chemical composite of al-bronze alloy are as following: 2 4 mass $\% \mathrm{Fe}, 8 \sim 10$ mass $\% \mathrm{Al}, 5 \sim 6$ mass $\% \mathrm{Ni}, 82 \sim 84$ mass $\% \mathrm{Cu}$.

Aluminum-bronze alloy was surfaced on low carbon steel with different process parameters. Then, specimens were acquired against to direction of the surfacing layer. The base metal side was brazed a $25 \mathrm{~cm}$ conductor with tin soldering. The corrosion was only taken at the surface of surfacing layer, so package treatment was used. After the treatment, the sample was put into self-fluxing $\mathrm{PH}=8.0$ artificial sea water solution with distilled water as solvent. The polarization curve was measured by SK II 98 system, the scanning rate was $1 \mathrm{mV} / \mathrm{s}$, the scanning area was $-1.15 \sim 0 \mathrm{~V}$. Three electrode electrolytic bath was used in this test and the saturated calomel electrode was used as reference electrode, platinum electrode was used as auxiliary electrode.

\section{Experimental results and discussion}

Microstructures and phase analysis of surfacing layer.

According to the equilibrium phase diagram of $\mathrm{Cu}-\mathrm{Al}$ binary alloy and $\mathrm{Cu}-\mathrm{Al}-\mathrm{Fe}$ ternary alloy ${ }^{[2]}$. 
The equilibrium organization of Al-bronze surfacing layer is composed of $\alpha$ solid solution (white), $\beta$ solid solution (gray) and $\kappa$ phase (black) which is distributed on $\alpha$ matrix.

Fig. 1 shows the microstructure of surfacing layer with different surfacing currents. When the current is $90 \mathrm{~A}$, the microstructure is composed of white and few grey $\beta$ phase. The white $\alpha$ phase shows as bamboo-like and needle-shaped in density, the $\beta$ phase is diffusion distributed among $\alpha$ phase (shown in Fig.1 a); With the increasing of surfacing current, the number of $\beta$ phase is increasing while the number of $\alpha$ phase is decreasing. When the current is $110 \mathrm{~A}, \beta$ phase is distributed among the matrix in rod or fishbone-shaped (shown in Fig. 1 b), $\gamma$ phase adhered grew up to flake and $\kappa$ wrapped in. When the current is $130 \mathrm{~A}, \alpha$ phase becomes coarse, $\beta$ phase is refined and shows as spotted or snowflake-shaped. The reason for this is that, $\mathrm{t}_{8 / 5}$ is longer, the bamboo-like and needle-shaped $\alpha$ phase grow and change into cylindrical grains. In the meantime, Fe element will diffuse from the base metal to surfacing layer through fusion area due to the high heat input. The Fe element will form over-saturated solution (black $\kappa$ phase), which wrapped with refined $\beta$ phase well-distributed on the matrix.
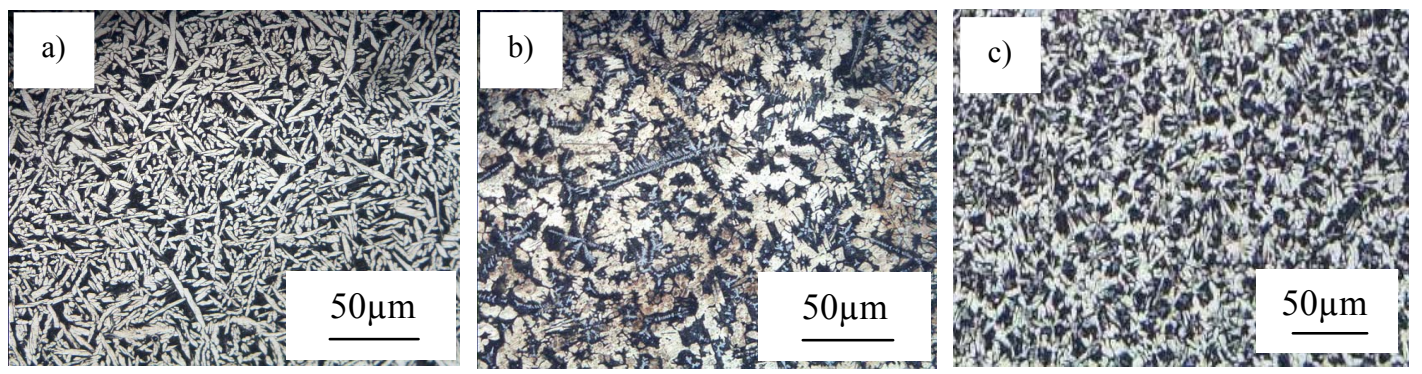

Fig.1 Microstructure of al-bronze surfacing layer under different welding currents a) $\mathrm{I}=90 \mathrm{~A}, \mathrm{~b}) \mathrm{I}=110 \mathrm{~A}$, c) $\mathrm{I}=130 \mathrm{~A}$

\section{$\mathrm{X}$-ray diffraction phase analysis of surfacing layer.}

In order to validate the deduction, which is discussed in fig.1. The X-ray diffraction is used to detect the phase of surfacing layer under different surfacing currents, the results show in Fig. 2. When the current is $90 \mathrm{~A}$, the major phase is $\alpha-\mathrm{Cu}, \beta$ is the minor phase; when the current is $110 \mathrm{~A}$, $\alpha-\mathrm{Cu}$ and $\beta$ phase are the major phases, with a small amount of $\kappa$ phase and $\gamma$ phase; when the current is $130 \mathrm{~A}$, the major phases are $\kappa$ phase and $\alpha-\mathrm{Cu}, \beta$ is the minor phase with $\kappa$ phase in scruple. From fig.2, it can be found that the phase of surfacing layer is same to the analyse shown in fig.1.

\section{Corrosion Resistance of surfacing layer and Influence factors.}

a)Corrosion Rate

Fig. 2 shows the corrosion rate of surfacing layer in 3.5\% $\mathrm{NaCl}$ solution with different surfacing currents. From fig.2, it can be found that the corrosion rate of all surfacing layers are very low, and they are all in the excellent level of corrosion resistance standard ${ }^{[3]}$. The littlest corrosion rate is found when the current is $90 \mathrm{~A}$, with the increase of welding current, corrosion rate is increasing.

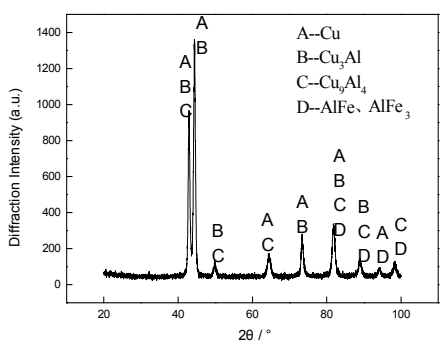

a) $\mathrm{I}=90 \mathrm{~A}$

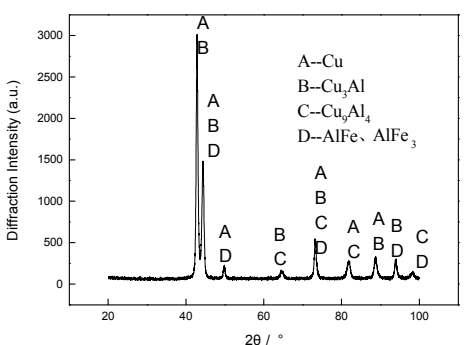

b) $\mathrm{I}=110 \mathrm{~A}$

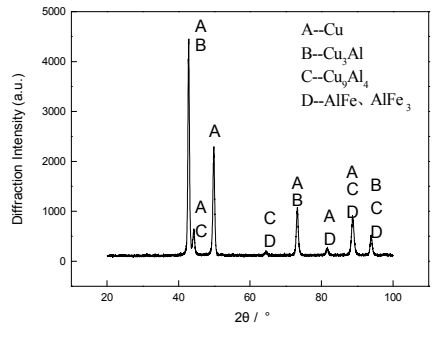

c) $\mathrm{I}=130 \mathrm{~A}$

Fig. 2 X-ray diffraction patterns of surfacing layer under different surfacing currents 


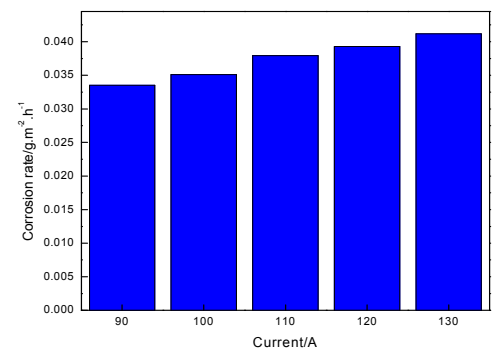

Fig. 3 corrosion rate of surfacing layer in $3.5 \% \mathrm{NaCl}$ solution with different surfacing currents b)Polarization Curve

Fig. 4 shows the tafel polarization curve of al-bronze surfacing layer in different currents. From Fig.4, it can be found that the polarization process is controlled by anode polarization for all different currents. For the anode polarization curves under different surfacing currents, corrosion potentials reduce with the increasing of electric currents, passivation phenomenon can not be found, but the change extent have a little difference among them. For cathode polarization curve, with the increasing of electrode potential, electric current increased gradually. The corrosion potentials of surfacing layer by the tafel polarization curve are listed in the table1. It is well-known to all, the higher the corrosion potential is, the better the corrosion resistance of surfacing layer is. So, the best corrosion resistance of al-bronze surfacing layer obtains when surfacing current is $90 \mathrm{~A}$. With the increasing of surfacing current, the corrosion resistance of surfacing layer is getting worse, which was agreement with the corrosion rate.

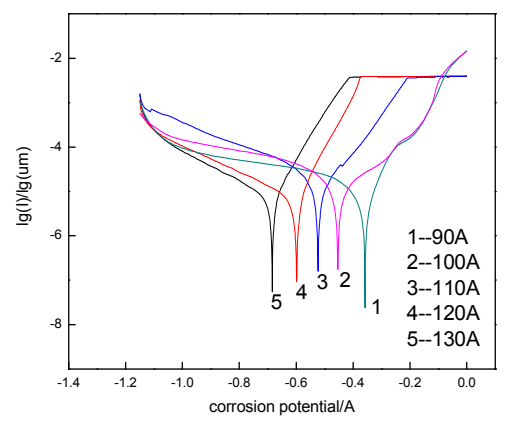

Fig.4 Tafel polarization curve of al-bronze surfacing layer in different conditions

Table 1 corrosion potential of al-bronze surfacing layer in different conditions

\begin{tabular}{ccccc}
\hline $90 \mathrm{~A}$ & $100 \mathrm{~A}$ & $110 \mathrm{~A}$ & $120 \mathrm{~A}$ & $130 \mathrm{~A}$ \\
\hline-0.3573 & -0.4533 & -0.5232 & -0.5989 & -0.6008 \\
\hline
\end{tabular}

\section{c)Influence Factors}

When the al-bronze alloys suffer an electrochemical corrosion, Dealuminification corrosion occurred preferentially. The reason for this is that there is potential difference between the copper and aluminum(The potential of $\mathrm{Al}$ is $-0.6 \mathrm{~V}$, and the potential of $\mathrm{Cu}$ is $+0.05 \mathrm{~V}$, formed a corrosion cell in $3.5 \% \mathrm{NaCl}$ solution ${ }^{[4]}$.), which makes al-bronze alloys under $3.5 \% \mathrm{NaCl}$ solution produce components selective corrosion.

According to electrochemical thesis, the higher positive the potential is, the more stable the metal is. Similarly the higher negative potential is, the less stable the metal is, the metal tends to erode. The $\alpha$ phase is the substitutional solid solution which matrix is $\mathrm{Cu}$, it has a higher corrosion potential, so its corrosion resistance is better. When the current is $90 \mathrm{~A}$, the microstructure of the al-bronze surfacing layer is consist of dense dendritic structure, the matrix $\alpha$ phase with few grey $\beta$ phase, so, the corrosion resistant is better. With the increasing of surfacing current, $\mathrm{Al}, \mathrm{Fe}$ element increasing, and migrating of atoms in the alloy make more $\beta$ phase generate. When the alloy is cooling to eutectoid temperature, $\beta$ phase eutectoid decomposition occurs: $\beta \rightarrow \alpha+\gamma$,orming the 
so-called "al-bronze pearlite" ${ }^{[5]}$. When the current is 110A, $(\alpha+\gamma)$ eutectoid will increase, and grow around $\kappa$ phase, decline corrosion resistance. The reason is that $(\alpha+\gamma)$ eutectoid of surfacing layer has significant preferential corrosion tendency, since $\gamma$ phase is continuously distributed in the $\alpha$ phase in $(\alpha+\gamma)$ eutectoid, which is a very dangerous anode relativing to $\alpha$ phase, and can be a passage that makes eutectoid organization corroded preferentially ${ }^{[6-8]}$. The $(\alpha+\gamma)$ eutectoid will become dispersed granular distribution when surfacing current is too big(130A), mainly because melting point of the $\mathrm{Fe}$ is higher, and easily form the core of nucleation in the solution. At the same time, the $\kappa$ phase increases, and $\mathrm{Ni}, \mathrm{Fe}, \mathrm{Al}$ elements enrich in $\kappa$ phase, which will cause the decreasing of $\mathrm{Al}$ around $\kappa$ phase and increase $\kappa$ phase interface energy. These will block the forming of alumina $\left(\mathrm{Al}_{2} \mathrm{O}_{3}\right)$, which protected the substrate alloy from further corrosion, so the corrosion resistance of the alloy reduces at last.

\section{Conclusions}

(1) The al-bronze alloy surfacing layer used in the experiment has good corrosion resistance in $3.5 \% \mathrm{NaCl}$ solution.

(2) When surfacing current is $90 \mathrm{~A}$, the surfacing layer has the best corrosion resistance, polarization potential is $-0.4533 \mathrm{~V}$, with the increasing of surfacing current, the corrosion resistance is becoming lower.

(3) $(\alpha+\gamma)$ eutectoid phase corrodes preferentially, $\alpha$ phase is a substitution solid solution based on $\mathrm{Cu}$ which has the best corrosion resistance

\section{References}

[1] Jiang J, Zhang P, Gao M T. Corrosion of metals[M]. Beijing: National Defense Industry press, 1986: $2-15$.

[2] Zhao Z D, Yao L J, Guo H Y. Handbook of copper and copper alloys[M]. Beijing: Science press, 1993.

[3] Zhu X R, Wang X R. Metallic materials of marine corrosion and protection[M]. Beijing: National Defense Industry press, 1999: 1-4.

[4] Li W S, Wang Z P, Lu Y. Corrosion resistance of Cu-14\%Al-X al-bronze alloy in $3.5 \% \mathrm{NaCl}$ solution[J]. The Chinese Journal of Nonferrous Metals, 2006, 16(3): 512-517.

[5] Han Z, Zhao H, Lin H C. TEM observation on dealuminification corrosion of QA19-2 alloy in marine environment[J]. The Chinese Journal of Nonferrous Metals, 2001, 11(3): 428-432.

[6] Ateya B G., Ashour E A, Sayed S M. Stress corrosion behavior of $\alpha$ Al-bronze in saline water[J]. Corrosion, 1994, 50(1): 20-25.

[7] Hashem A, Caceres P G, Riad W T. Cavitation corrosion behavoior of cast nickel-aluminum bronze in sea-water [J]. Corrosion, 1995, 51(50): 331-342.

[8] Han Z, Jiang W M, Lin H C. Study on corrosion of aluminum bronze in sea water pipe line system[J].Chinese Journal of corrosion and protection, 2000, 20(6):188-192.

E-mail:su_yunhai@yahoo.com.cn

Tel:13709840941 